\title{
Religiosidade: 43 anos de história de um exercício de pesquisa
}

\author{
Geraldina Porto Witter
}

\section{Apresentação}

Como o objetivo do trabalho é apresentar e comentar um exercício de pesquisa, que é aqui transcrito, para evitar confundir o leitor denominou-se esta parte de apresentação. Para contextualizar o documento é preciso retomar um pouco a sua história.

Como hoje, os conceitos de religiosidade e espiritualidade não tinham entre os pesquisadores um consenso (Buskits e Davis, 2006). Hoje, mais freqüentemente define-se religiosidade como a importância atribuída e a freqüência de (a) crenças religiosas, (b) práticas religiosas, (c) aplicações das crenças e (d) participação nos serviços e atividades de grupo da religião. (Leonard, 2006).

Arrumando as coisas da Autora sua secretária particular encontrou o manuscrito do exercício de pesquisa com o título - Desenvolvimento de Alguns Conceitos Religiosos na Adolescência, $O$ texto foi produzido para a disciplina de Psicologia do Desenvolvimento, ministrada pelo Dr. Romeu de Moraes Almeida, no Curso de Especialização em Psicologia Educacional, ministrado na Cadeira de Psicologia Educacional, da Faculdade de Filosofia, Ciências e Letras da Universidade de São Paulo, sob a coordenação de seu titular Prof. Doutor Arrigo Leonardo Angelini. $\mathrm{O}$ ano era 1964. Como parte das atividades acadêmicas da disciplina cada aluno ou dupla de pesquisa deveria fazer um trabalho de pesquisa, sobre qualquer aspecto do desenvolvimento, tendo por sujeitos, pessoas de qualquer idade. Por morar fora de São Paulo e pela dificuldade de encontrar os colegas fora de horário de aula a opção foi por trabalhar só na atividade. Isto deu liberdade maior na tomada de decisão quanto ao tema, sujeitos, método, mas também não foi possível contar com um grupo para discussão e partilhar as responsabilidades, o que certamente é uma estratégia efetiva na produção de texto (Staats, 1983, Wepner \& Grambell, 2006). Como hoje, na maioria das situa- ções não havia também a preocupação em se orientar e criar o hábito de trabalho articulado em grupo.

Pouquíssimas pessoas davam continuidade aos estudos de graduação mesmo em termos de cursos de especialização. As turmas em cada disciplina raramente passavam de 10 alunos. A turma de desenvolvimento era "grande", de uns 12 a 14 alunos. Não havia quase textos em português, periódicos nacionais eram pouquíssimos, os livros na maioria eram traduções. Havia em cada cadeira uma pequena biblioteca, sem bibliotecário no caso da Psicologia Educacional, sendo cuidada e gerenciada pelos próprios professores, que se revezavam nos poucos horários em que ela ficava aberta aos alunos. Mas já então se podia contar com um acervo de periódicos estrangeiros. Só após a reforma universitária, com a criação do Instituto de Psicologia, foram reunidos os acervos das bibliotecas das Cadeiras de Psicologia para formar a hoje denominada Biblioteca Dante Moreira Leite do Instituto de Psicologia da USP.

$\mathrm{Na}$ ocasião da realização do trabalho só se podia consultar o acervo na própria biblioteca e, vale lembrar aos mais jovens, não havia como fazer cópias das matérias de maior interesse. Era ler e resumir o texto em fichas, cadernos etc (não existia cópia xerográfica). Quando não se dispunha do periódico a única forma de obter o texto era escrever para o autor (outra dificuldade hoje superada) e pedir uma separata. Quando se encontrava alguém disposto a colaborar, eram meses de espera para o material chegar via correio. Americanos e canadenses eram mais cooperativos que os europeus. Mas o tempo era muito para se esperar, mas era só o que se podia fazer. $O$ intercâmbio entre as bibliotecas era precário mesmo quando existia e se dava graças por isto. Quando se dispunha de poucos meses para realizar a tarefa era difícil a empreitada.

A opção pelo tema decorreu de muito se falar já na época da chamada crise de religiosidade na adolescência, embora não se visse concomitantemente uma 
valorização do pesquisar a matéria. $\mathrm{Na}$ falta de maiores informações de cunho nacional e sendo o Brasil um país multicultural em que convivem em harmonia as várias religiões pareceu oportuno verificar como os adolescentes conceituavam ou pensavam sobre alguns aspectos da religiosidade. Considerando-se que o trabalho deveria realizar-se e ser apresentado em poucos meses (4 meses no máximo, março a junho) esta contingência influiu nas opções metodológicas e de análise de dados. Vale lembrar que a ética de pesquisa era aprendida desde a graduação e os professores eram os modelos e orientadores para se evitar cometer alguma falta. Também não havia Comitês de Ética em Pesquisa (só vão aparecer no Brasil nos anos 90 do século $X X$ ). Mas o respeito aos princípios éticos era uma constante.

Havia grande aceitação nas escolas da presença de pesquisadores e não foi difícil obter autorização para a coleta de dados quer por parte da Direção e Orientação Pedagógica, quer dos pais consultados durante reuniões, ou mesmo dos alunos. A "palavra dada" tinha tal valor que sequer alguém pensaria, na ocasião, em obter termos de consentimento por escrito, hoje imprescindíveis. $O$ desejo dos adolescentes em participar, a curiosidade quanto aos resultados eram fortes. Sempre, após conduzido o trabalho se voltava às escolas para uma breve apresentação dos resultados. Fazia parte da rotina da pesquisa. O mesmo ocorreu com os dados aqui resgatados daquela vivência. Houve manifestação de alegria e surpresa nas convergências e tentativas de explicar e defender as divergências. $O$ que deveria levar uns 20 minutos durou, pelo menos, duas horas-aula fora as conversas de corredor que se seguiram, pois os alunos ficaram muito interessados em saber o que tinha sido apurado.

No final do semestre os estudantes de especialização apresentavam ao professor, por escrito, um relatório, no formato de artigo, dos resultados do exercício de pesquisa, Também faziam a apresentação para os colegas sob a forma de comunicação oral, nos moldes do usual em eventos científicos. Além disso participavam de visitas dirigias a instituições, observações de crianças, faziam seminários baseados em textos, alguns participavam como auxiliares de pesquisas realizadas pelos docentes. Considerando que se cursava simultaneamente 4 disciplinas, isto implicava em muita atividade posto que para cada uma delas se fazia pelo menos um exercício de pesquisa entre outras atividades.

Segue-se aqui em itálico cópia literal do trabalho realizado em 1964, conforme foi entregue ao docente responsável excluindo-se apenas o resumo e o abstract, para evitar possível redundância ou confusão com o que é agora apresentado., As referências do exercício seguiam padrão distinto dos que hoje estão em uso.

\section{Desenvolvimento de alguns con- ceitos religiosos na adolescência}

\section{Introdução}

Em 1958, Feifel (1958) declarou, num Simpósio sobre religião e saúde mental, que nos últimos anos as relações entre a ciência e a religião, estavam tomando direções auspiciosas conforme atestam os seminários sobre religião e psiquiatria, o trabalho conjunto de pastores e psicoterapeutas, bem como outros esforços que se faziam sentir nesta direção. Entretanto, poucos trabalhos têm sido feitos tendo por objetivo possibilitar um melhor conhecimento do comportamento religioso tanto que, em 1964, Havens, na introdução de seu estudo sobre conflito religioso em adolescentes relata ter encontrado poucas investigações significativas abordando o problema de mudanças na religiosidade em adolescentes. $O$ mesmo tem ocorrido em relação a outros aspectos deste comportamento. Contudo, como lembra Clark (I96I), o estudo deste comportamento não interessa apenas a quem esteja preocupado com o estudo de desenvolvimento ou de ajustamento, mas também aos que se preocupam com a motivação, a socialização e a educação.

Sem ter a pretensão de contribuir com dados decisivos para esta área de estudo, resolveu-se explorar alguns aspectos relacionados com o comportamento religioso em adolescentes brasileiros. $O$ objetivo era saber como jovens de religiões diferentes e jovens sem religião definem alguns conceitos relacionados com a religião e a vida após a morte. 


\section{Método}

\section{Sujeitos e Procedimentos}

Pediu-se a cerca de 2300 alunos de ambos os sexos, do curso secundário matriculados no Instituto de Educação "Dr. Washington Luís", de Mogi das Cruzes, em 1964, que fornecessem por escrito dados pessoais relativos a sexo, idade, nacionalidade, nível sócio-econômico, grau de escolaridade e religião, devendo ainda responderem às questóes: I) o que pensa de Deus?; 2) ० que pensa de Jesus Cristo?; 3) ० que quer dizer ser cristão?; 4) o que é o pecado? e 5) o que pensa que acontece após a morte? Estas perguntas foram sugeridas pelo estudo de Cooper (196I) que as incluiu no teste de idéias religiosas que aplicou a estudantes dos cursos de psicologia do BercaCollege.

Tendo colhido o material foram separados os diversos grupos religiosos e formados grupos paralelos de sujeitos católicos para cada grupo de outra religião encontrado e que dispusesse de mais de cinco sujeitos. Os sujeitos dos diversos grupos religiosos foram emparelhados com sujeitos católicos em relação à nacionalidade, sexo, idade cronológica, nível sócioeconômico e grau de escolaridade. Como resultado deste emparelhamento, em que foram controladas cinco variáveis, os sujeitos ficaram reduzidos a 256 , sendo 128 do gênero masculino e 128 do feminino, podendo ser visto na Tabela I o agrupamento feito pelos diversos grupos religiosos paralelos.
Observe-se que no emparelhamento foram constituídos grupos masculinos e femininos atendendo também à idade cronológica, isto é, adolescentes de 12 a 15 anos e de 16 a 19 anos inclusive. Porém muitas vezes foi feito o remanejamento dos grupos sem levar em conta os dois grupos etários conforme se poderá ver na parte referente aos resultados. Vale esclarecer que se optou por proceder desta maneira face aos próprios dados colhidos, isto é quando as diferenças encontradas nos grupos etários diferentes não eram significantes.

\section{Resultados}

O maior grupo religioso encontrado entre os sujeitos foi naturalmente o católico, religião dominante na região. O grupo mais numeroso depois do católico foi o dos budistas o que se explica pelo fato da colônia japonesa ser bastante numerosa na cidade. No grupo de idade de 12 a 15 anos foram encontrados apenas três rapazes que declararam não ter religião, porém, no grupo de 16 a 19 anos registrou-se 18 rapazes e seis moças, portanto aproximadamente $10 \%$ da população estudada, declarando não ter religião.

A análise das respostas às diversas perguntas feitas aos sujeitos deu o seguinte resultado: das características apontadas como elementos integrantes do conceito de Deus a concepção Dele como Ser Cria-

Tabela I - Número de Sujeitos nos diversos Grupos Religiosos Paralelos

\begin{tabular}{|c|c|c|c|c|c|c|c|c|c|}
\hline \multirow[b]{2}{*}{ Sexo e Idade } & \multicolumn{9}{|c|}{ Religião } \\
\hline & Espírita & Católico & Budista & Católico & Protestante & Católico & $\begin{array}{c}\text { Sem } \\
\text { Religião }\end{array}$ & Católico & Total \\
\hline $\begin{array}{l}\text { Masculino } \\
(12-15 \text { anos })\end{array}$ & 10 & 10 & 18 & 18 & - & - & - & - & 56 \\
\hline $\begin{array}{l}\text { Masculino } \\
(16-19 \text { anos })\end{array}$ & - & - & 18 & 18 & - & - & 18 & 18 & 72 \\
\hline $\begin{array}{l}\text { Feminino } \\
(12-15 \text { anos })\end{array}$ & 10 & 10 & 23 & 23 & 12 & 12 & - & - & 90 \\
\hline $\begin{array}{l}\text { Feminino } \\
(16-19 \text { anos })\end{array}$ & 5 & 5 & 8 & 8 & - & - & 6 & 6 & 38 \\
\hline Total & 25 & 25 & 67 & 67 & 12 & 12 & 24 & 24 & 256 \\
\hline
\end{tabular}


dor é a mais comumente lembrada, Entre os sujeitos femininos $40 \%$ das moças entre 12 e 15 anos e $37 \%$ das moças entre 16 e 19 anos apontaram esta característica nas suas concepções de Deus. O mesmo ocorreu entre os sujeitos masculinos sendo que $36 \%$ dos rapazes entre 12 e 15 anos e $33 \%$ dos rapazes entre 16 e 19 anos apresentaram esta concepção de Deus. Em segundo lugar, como característica mais comumente atribuída a Deus pelos rapazes do primeiro grupo etário (34\%) aparece a concepção de Deus como um Ser Superior, o mesmo aconteceu entre os rapazes mais velhos (29\%). Entre as moças do primeiro grupo $29 \%$ também considerou Deus como um Ser Superior, enquanto que as do grupo etário superior lembraram igualmente as características: onipotência (I4\%) e superioridade (I4\%). Por ordem de freqüência as características atribuídas a Deus por todos os grupos religiosos paralelos, masculinos e femininos, são: criatividade, superioridade, onipotência e oniciência.

No grupo de sujeitos femininos sem religião 33\% declarou que Deus não existia enquanto que seu grupo paralelo (católico) apresentou resultados seguindo a linha geral acima exposta, isto é, dando a idéia de que Deus é um Ser Criador (50\%), Superior (33\%) e Onipotente (I7\%). Fato semelhante registra-se nos grupos paralelos sem religião - católico para o sexo masculino, sendo que, $39 \%$ dos rapazes sem religião negaram a existência de Deus enquanto que no seu grupo paralelo houve a mesma ênfase dada às carac- terísticas: Criador (50\%), Superior (28\%) e Onipotente (22\%). Entre os sujeitos sem religião foram comuns afirmações de que Deus é a natureza ou é um enigma. Por exemplo, um rapaz de 18 anos escreveu que Deus é "uma força natural, ou melhor, a própria natureza" enquanto que outro, de 19 anos, escreveu: "Deus é o resultado do medo e da fraqueza da raça humana: um escape".

$\mathrm{Na}$ Tabela 2 aparecem os resultados de $\chi^{2}$, medida usada para verificar a dependência ou independência das crenças religiosas dos sujeitos e suas concepções de Jesus Cristo como um Ser divino ou como um Ser humano.

A hipótese nula era que Jesus Cristo não seria considerado como um Ser humano pelos diversos grupos religiosos, isto é, não há relação entre o grupo religioso a que pertence a pessoa e sua concepção de Cristo $\left(\chi^{2}=0\right)$. Os dados não rejeitaram esta hipótese para todos os grupos paralelos religiosos conforme se pode verificar na Tabela 2. Comparando os $\chi^{2}$ obtidos, através do $T$ de Tchuprow, constatou-se que no conceito de Cristo como Ser divino é menos dependente entre espíritas e católicos ( $T-0,010)$ do grupo etário de 16 a 19 anos. Entre budistas e católicos encontramos um $\mathrm{T}=0,22$ indicando uma dependência pouco maior que a encontrada para os outros grupos religiosos, porém ainda baixa. Provavelmente isto ocorreu devido às diferenças religiosas entre budismo e catolicismo serem maiores do que entre o catolicismo e as demais religiões considera-

Tabela 2 - Resultado do $\chi^{2}$ na verificação da relação de dependência entre a religião e a opinião mantida com relação a Jesus Cristo, sendo $\chi^{2}(p=0,10$. I) $=2,706$

\begin{tabular}{llcc}
\hline Idade & Grupos Paralelos & $\chi^{2}$ & $\mathrm{H}_{\mathrm{o}}\left(\chi^{2}=0\right)$ \\
\hline \multirow{3}{*}{$12-15$ anos } & Protestante - católico & 1,664 & não rejeitada \\
& Budista - católico & 1,872 & não rejeitada \\
& Espírita - católico & 0,020 & não rejeitada \\
& Budista - católico & 1,915 & não rejeitada \\
$16-19$ anos & Espírita - católico & 0,092 & não rejeitada \\
& Sem religião - & 10,872 & rejeitada \\
& católico & & \\
\hline
\end{tabular}


das no presente estudo. Apenas nos grupos paralelos sem religião - católico verificou-se a rejeição da hipótese indicando que provavelmente há dependência entre o fato da pessoa considerar Cristo um Ser humano e ela ter ou não religião. Entretanto, conforme indica $\circ \mathrm{T}=0,52$ trata-se de uma dependência média, possivelmente não sendo mais alta porque entre os jovens sem religião muitos acreditam em Deus (29\%) e vêem Cristo como Seu filho (20\%) ou como Salvador Espiritual do Mundo (10\%). co, ter religião, ser bom e ser batizado.

No grupo feminino de 12 a 15 anos verificou-se o seguinte: nos grupos paralelos protestante-católico $50 \%$ dos sujeitos protestantes afirmou que ser cristão é obedecer a Deus, $35 \%$ que é seguir os ensinamentos de Cristo, enquanto que no seu grupo paralelo houve maior dispersão de opinião tendo $25 \%$ afirmado que era seguir Cristo e o resto do grupo dispersou sua opinião por muitos itens. Nos grupos paralelos espírita-católico houve concordância de

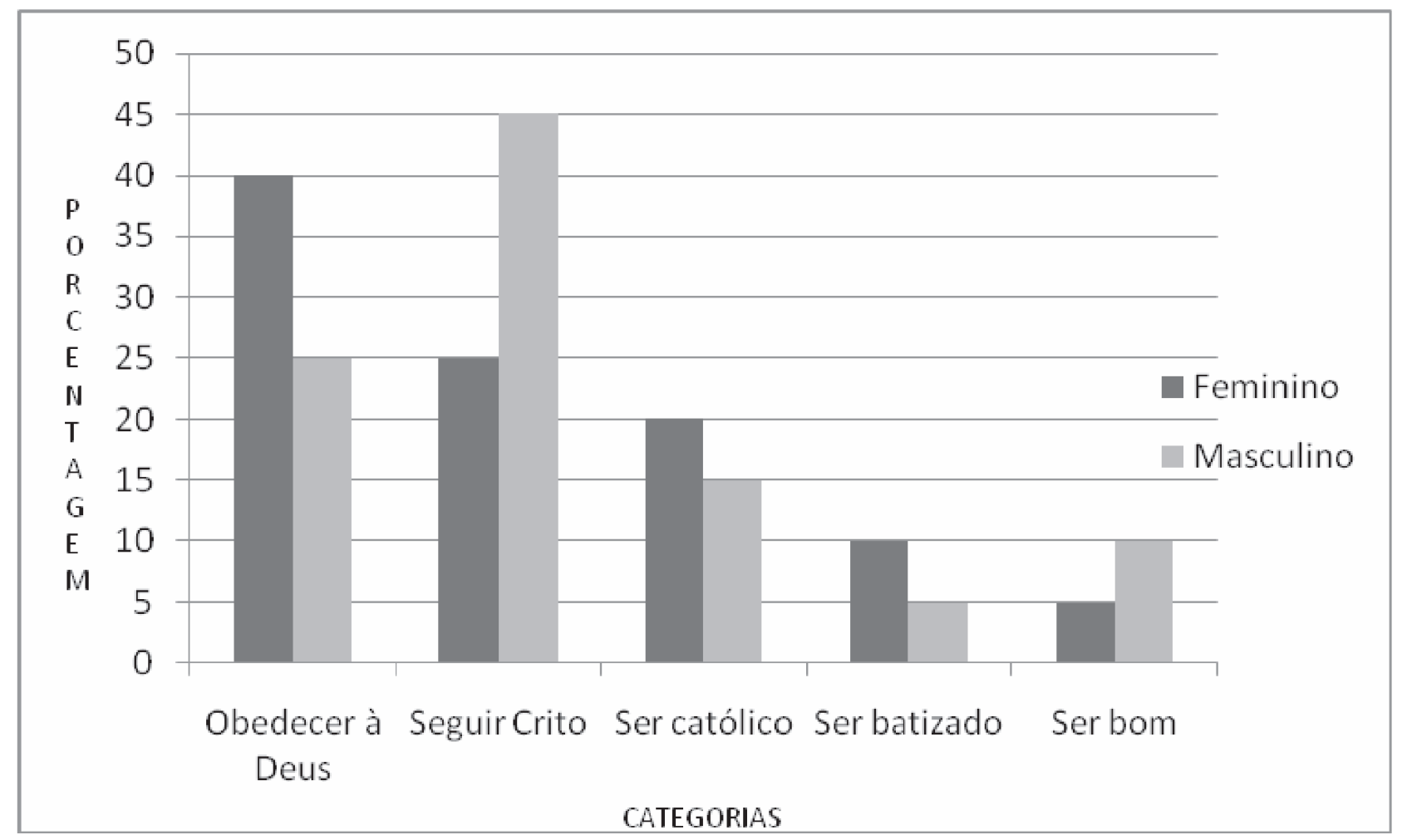

Figura I - Opinião de Adolescentes Masculinos e Femininos quanto ao que quer dizer ser Cristão

A Figura I apresenta a opinião de adolescentes masculinos e femininos, independentemente da idade, quanto ao que quer dizer ser cristão, tendo se registrado uma variação muito grande nas opiniões quanto ao que quer dizer ser cristão para ambos os sexos. Pela ordem decrescente de freqüência os sujeitos femininos responderam a este item indicando que ser cristão é obedecer a Deus, seguir Cristo, ser católico, ter religião, ser batizado e ser bom. Nos rapazes, segundo a mesma ordem de freqüência, ser cristão é seguir Cristo, obedecer a Deus, ser católi- opinião sendo o obedecer a Deus escolhido por $30 \%$ dos sujeitos de cada grupo. Dos sujeitos budistas $60 \%$ não respondeu a esta questão, mas os que responderam concordaram com a opinião do seu grupo paralelo católico quanto a afirmação mais freqüente, isto é, de que ser cristão é obedecer a Deus. Entre as moças de 16 a 19 anos houve sempre concordância entre os grupos paralelos religiosos, não havendo apenas entre os grupos sem religião - católicos, sendo que $50 \%$ do grupo, sem religião, afirmou que ser cristão era seguir Cristo, enquanto que no seu grupo 
paralelo, de católicos, a afirmação mais freqüente foi a de que ser cristão é ser católico (33\%).

Nos vários grupos paralelos dos rapazes, para os dois grupos etários e mesmo para os sem religião, houve maior concordância do que entre os sujeitos femininos aparecendo sempre como mais freqüente a afirmação de que ser cristão é seguir Cristo. Isto ocorreu mesmo entre os grupos paralelos: sem religião - católico. No grupo masculino houve menor dispersão que no feminino.

Quanto ao pecado houve sempre concordância entre os diversos grupos paralelos, masculinos e femininos aparecendo como mais freqüente a afirmação de que pecar é cometer qualquer má ação, sendo que $54 \%$ das moças e $48 \%$ dos rapazes fizeram esta afirmação. Com $21 \%$ das meninas e $34 \%$ dos meninos afirmam que o pecado é uma desobediência a Deus, esta concepção de pecado aparece em segundo lugar quanto a freqüência. Mesmo o grupo de sujeitos que declarou não ter religião, não diferiu dos demais quanto à resposta a esta questão. Mas é no último grupo que se registraram as respostas mais originais em relação às dos demais sujeitos. Entre as respostas dos sujeitos sem religião algumas afirmaram a não existência de pecado e outras que afirmaram ser o pecado um desrespeito às leis sociais ou morais.

Como resposta ao que acontece após a morte, surgiram as seguintes concepções: a alma vai para $\circ$ céu ou para o inferno conforme seus atos; a alma reencarna; tudo acaba com a morte e há ainda os que declaram ser para eles uma incógnita o que acontece então.

Os sujeitos apresentaram dúvida crescente com a idade quanto ao que acontece após a morte. Sendo que isto se constatou em $20 \%$ dos adolescentes entre 12 e 15 anos e em $25 \%$ dos adolescentes de 16 a 19 anos.

Para verificar a hipótese - 0 fato do sujeito pertencer a determinados grupos religiosos não afeta sua maneira de encarar o após morte - calculou-se a relação de independência entre as variáveis: religião e concepção do após a morte por meio do cálculo de $\chi c^{2}$. Na Tabela 3 estão expressos os resultados destes cálculos devendo observar-se que $\chi \mathrm{c}^{2}(\mathrm{p} \leq 0,05)=5,991$.

Pela Tabela 3 pode-se verificar que o único caso de não rejeição da hipótese verificou-se entre os grupos paralelos de protestantes e católicos. Nos demais casos parece provável que a maneira pela qual os adolescentes vêm o futuro é dependente da religião por eles professada. Os dados obtidos indicam uma maior dependência no caso de budistas e católicos $(T=0,62)$ do que entre espíritas e católicos $(T=0,49)$ e sem religião e católicos $(T=0,45)$. Como os grupos foram emparelhados em diversos aspectos, é possível que as diferenças encontradas sejam devidas às diferenças de crenças religiosas, neste caso não há diferença relevante entre o que protestantes e católicos pensam ocorrer após a morte. A dependência encontrada no caso dos grupos sem - religião - católicos não é maior possivelmente porque $12 \%$ dos sujeitos que se declararam sem religião acredita na concepção da existência do céu e do inferno e $4 \%$ destes sujeitos acredita na possibilidade da reencarnação.

No início da adolescência, dos sujeitos femininos foram os protestantes - católicos os que se assemeIham entre si e os budistas - católicos os que mais se

Tabela 3 - Resultados de $\chi^{2}$ com relação a opinião de adolescentes de diversas religiões quanto ao que ocorre após a morte

\begin{tabular}{lrl}
\hline \multicolumn{1}{c}{ Grupos Paralelos } & \multicolumn{1}{c}{$\chi^{2}$} & $\mathrm{H}_{\mathrm{o}}: \chi^{2}=0$ \\
\hline espírita - católico & 21,600 & rejeitada \\
protestante - católico & 2,625 & não rejeitada \\
budista - católico & 71,372 & rejeitada \\
sem religião - católico & 20,041 & rejeitada \\
\hline
\end{tabular}


distanciam havendo cerca de $60 \%$ de budistas com dúvidas relativas ao que ocorre após a morte. Nesta mesma fase, entre os sujeitos masculinos, houve maior concordância entre budistas e católicos, sendo que $70 \%$ dos primeiros e, $88 \%$ dos segundos acreditam na existência do céu-inferno; a menor concordância verificou-se entre espíritas e católicos visto que $70 \%$ dos primeiros acreditam na reencarnação e a totalidade dos segundos acredita na concepção céu-inferno. Na fase final da adolescência entre os sujeitos femininos houve maior concordância entre budistas e católicos, sendo que aproximadamente $60 \%$ destes dois grupos, religiosos pressupõem a existência do céu e do inferno. Entre as moças a menor concordância encontrada verificou-se entre os grupos espírita e católico sendo que a totalidade dos sujeitos do primeiro destes grupos crê na reencarnação enquanto que $80 \%$ do seu grupo paralelo crê na existência do céu-inferno. Entre os rapazes de 16 a 19 anos, houve mais concordância entre os budistas e católicos, sendo que nos dois grupos $70 \%$ acredita na existência do céu e do inferno e $20 \%$ tem dúvidas quanto ao que acontece após a morte. Para este sexo e idade registrou-se menor semelhança de opinião entre os sem religião e os católicos sendo que dos primeiros $50 \%$ vê no após morte uma incógnita e, somente $5 \%$ crê no céu e inferno, enquanto que no seu grupo paralelo $81 \%$ acredita no céu-inferno e somente $17 \%$ tem dúvidas quanto ao que possa ocorrer após a morte.

\section{Discussão}

Os dados parecem confirmar resultados de diversas pesquisas que levaram Landis (1952), Crow e Crow (1956) e outros ao apontar o início da segunda fase da adolescência como a idade mais favorável para a conversão e o desenvolvimento de tendências ateístas e agnósticas.

Parece que algumas áreas de indecisão crescente como a existência de Deus e o que ocorre após a morte possam ser resultantes do avanço na escolaridade o que coloca os sujeitos em contato com áreas de estudo mais avançado em ciências naturais e hu- manas, conforme sugerem Kuhlen e Arnold (1944) ao explicar seus resultados Porém estes autores e mesmo Crow e Crow (1956) lembram, que estas indecisões podem ser resultado de discussões com colegas e adultos ou indicar apenas uma atitude de julgamento suspenso, entretanto, os dados não permitem fazer qualquer afirmação neste sentido, pois tais variáveis não foram controladas no presente estudo.

O fato de diversos grupos religiosos terem preferencialmente descrito Deus como Criador de tudo e de todos, leva a considerações de que possivelmente este seja $\bigcirc$ aspecto mais destacado na instrução religiosa no que diz respeito a Deus. Os resultados mostraram que a concepção de Jesus Cristo como um Ser Divino ou Humano depende do sujeito ter ou não religião e neste último caso, da religião que professa. Quanto ao que quer dizer ser Cristão os meninos parecem estar melhor instruídos do que as jovens sendo igualmente possível dizer que os sujeitos católicos, de ambos os sexos, são os que menos cultura religiosa parecem ter pois mais do que qualquer outro grupo religioso reduzem o cristianismo ao catolicismo.

A maior harmonia quanto às idéias relativas ao pecado parecem sugerir uma maior semelhança entre a experiência religiosa dos diversos grupos com relação a este assunto. Porém, parece possível que e noção não seja essencialmente dependente da experiência religiosa do adolescente, mesmo em idades anteriores. Provavelmente a noção de pecado esteja mais ligada a aprendizagem ética. Pois, conforme lembra Landis (1952) na cultura cristã identificam-se religião e moralidade e a criança tem pouca possibilidade de discriminar entre as atividades éticas e religiosas. Porém segundo o referido autor isto já pode ocorrer na adolescência, sendo mesmo possível que esta discriminação seja uma das causas do aparecimento do ceticismo nesta fase da vida. Diante destas considerações parece que a concordância de todos os sujeitos com relação ao que seja o pecado se deva menos à semelhança de experiência religiosa do que à semeIhança de experiência ética.

Os dados estão de acordo com os resultados de Kunhlen e Arnold (1944) no que diz respeito ao au- 
mento de dúvidas e incertezas relativas ao após a morte, porém de uma maneira menos acentuada do que aquela relatada pelos referidos autores. Possivelmente isto seja devido às diferenças culturais.

O fato dos grupos protestante - católico aproximarem-se mais quanto à opinião que têm sobre o após a morte, possivelmente seja resultado das doutrinas religiosas seguidas por estes grupos diferirem menos entre si do que aquelas aceitas pelos outros grupos quanto a este particular.

Em face dos resultados obtidos é possível afirmar que os conceitos relativos a Jesus Cristo e ao que acontece após a morte dependem mais da pessoa ser ou não religiosa. $O$ conceito de Deus e o que é ser cristão parecem ser mais dependentes da religião professada pelo adolescente do que do fato dele ter ou não religião. Quanto ao conceito de pecado parece ser independente da religião e do fato da pessoa ser ou não religiosa.

\section{Referências}

I. CLARK, W.H, Religion as a response to the search for meaning; its relation to skepticism and creativity. Acta Psychologica, I96I, XIX, 640-643.

2. COOPER, C.C. Patterns of Religious Ideas and Personality Traits In Berca College Students. Acta Psychologica, 196I, XIX, 654-655.

\section{CROW, L.D. \& CROW, A. Adolescent Development and}

Adjustment. New York. McGraw Hill Book Company, Inc. 1956.

4. FEIFEL, H. Symposium on relationships between religion and mental health: Introductory remarks. American Psychologist, 1958, 13, 565-566.

5. HAVENS, J.A. Study of Religious Conflict in College Students. J.Soc. Psychol., 1964, 64, 77-78.

6. KUNHLEN, R.G. \& ARNOLD, M. Age differences in religious beliefs and problems during adolescence. J. Gen. Psychol., 1944, 65, 29I-300.

7. LANDIS, P.H. Adolescence and Youth. The process of maturing ( $2^{\mathrm{a}}$ ed.) New York, McGraw Hill Book Company, Inc. 1952.

\section{Comentários}

O primeiro aspecto a considerar diz respeito às contingências gerais de realização do exercício acadêmico de pesquisa na época. Havia na USP, embora se destaque aqui o curso de especialização em Psicologia Educacional, um clima de constante solicitação à pesquisa nas disciplinas e estímulo para se envolver como auxiliar nas pesquisas que os docentes estavam conduzindo. Raramente um professor, mesmo na graduação não fazia solicitações neste sentido. Não havia uma programação oficial de iniciação científica, nem havia bolsas para tanto. Tudo o que movia os alunos nesta direção eram os docentes enquanto modelos, entusiasmados, competentes e éticos. Poder acompanhar o trabalho deles como auxiliar de alguma de suas pesquisas era uma oportunidade única de aprendizagem. Nada podia ser mais importante para o estudante do que aprender. $\mathrm{O}$ envolvimento era intenso, desde a graduação, além das pesquisas-exercício das várias disciplinas muitos alunos faziam o papel do que mais tarde se passou a denominar monitoria e auxiliar de pesquisa. Não havia registros, certificados, ou qualquer preocupação em ganhos financeiros. $O$ importante era aprendizagem extra-curricular que tais oportunidades representavam.

$\mathrm{Na}$ especialização era a mesma cultura que vigorava, as disciplinas requeriam horas de prática profissional, de pesquisa e outras atividades. As solicitações para auxiliar em pesquisas dos docentes lecionando ou não nos cursos eram freqüentes. Quando o aluno dispunha de condições envolvia-se em várias pesquisas, por vezes, fazia além da exigida na disciplina outros exercícios de pesquisa. A orientação, o estímulo e a atenção dos outros professores eram variáveis essenciais. A motivação para pesquisar que para muitos começava nos primeiros anos de graduação se intensificava na especialização. Certamente como não havia paralelamente estímulo para a publicação, os exercícios de pesquisa paravam na primeira redação e acabavam, em sua grande maioria, esquecidos em alguma pasta como o aqui apresentado, ou simplesmente destinados ao lixo. Assim muito dado deve ter sido perdido. Hoje, com o estímulo à publicação há um maior empenho em chegar à redação final tendo 
em vista o envio a eventos e periódicos. Houve progresso sensível quanto as isto mas parece que já não há o mesmo ela pela pesquisa entre docentes e alunos. A Iniciação Científica passou a ser privilégio de poucos alunos bolsistas. O privilégio resultou em benefício de alguns mas a maioria pode estar se formando sem as bases para ser um profissional-pesquisador, o que é lastimável (Buskist \& Davis, 2006).

Tecidas estas considerações gerais enfoca-se a seguir a questão mais especificamente relacionada com o tema do trabalho encontrado. Para dispor de uma perspectiva geral foi feito um levantamento no PsychINFO (0I/03/2007) relativo a 2006-2007. No período só três livros incluíram o tema religiosidade e adolescência. Rochlkepartain, King, Wagner, Benson (2006), Bear e Minke (2006) e Jimerson e Furiong (2006) e incluindo alguns textos sobre o assunto. Foram cadastradas 9 teses que de alguma forma trataram do tema e que são a seguir apresentadas.

Mulliken (2006) estudou o "mito do estupro/rapto", isto é, que se cria socialmente uma hostilidade em relação às vítimas de violência sexual, ou seja, é uma representação de amplos construtos sociais, decorrentes do racismo e do sexismo. Analisando a aceitação do mito entre universitários, de ambos os gêneros, verificou-se que a aceitação do mito, e as atitudes negativas em relação às vítimas é maior entre os homens, os jovens religiosamente mais tradicionalistas e fundamentalistas também aceitam mais o mito, o mesmo ocorrendo mais entre descendentes de asiáticos do que entre outros grupos (brancos). Entretanto, níveis altos de religiosidade não se correlacionaram nem foram preditivos de aceitação do mito de atitudes negativas em relação às vítimas. No Brasil há carência de dados sobre a existência do referido mito e como ele ocorre em todo o ciclo de vida.

Kaplan (2006) estudou a relação entre religião e desenvolvimento da identidade entre 119 adolescentes muçulmanos ( $2^{\mathrm{a}}$ geração) vivendo nos Estados Unidos. Eram moderadamente religiosos mas os descendentes de árabes eram mais religiosos; os descendentes de turcos eram menos presos aos padrões culturais de seus antecessores. Os islâmicos que se auto-identificavam como tal tendiam a rejeitar a integração com os valores americanos, os islâmicos que também se consideravam americanos consideravam possível ser parte da sociedade americana sem abandonar sua cultura tradicional.

O trabalho de Eghikudje (2006) encontrou a religiosidade como uma variável que contribuía positivamente no afastamento psicossocial de adolescentes nigerianos que viviam com pais portadores de AIDS, evitando problemas biopsicossociais. Rodriguez (2006) verificou que cognição, atitudes e fatores sociais estão associados com o controle da gravidez entre os adolescentes o mesmo não ocorrendo com a religião e religiosidade.

Em um estudo exploratório dos fatores espirituais, religiosos, clínicos e sociais em orientação religiosa de adolescentes, Hostetter (2006) encontrou relações estatísticas em nível significativo entre as respostas a um questionário específico e idade, enfrentamento religioso positivo e ansiedade. Encontrou relações significantes negativas com enfrentamento religioso negativo, atividade religiosa pessoal e afiliação à religião muçulmana ou ao ateísmo. As referidas relações eram modestas.

Leonard (2006) estudou o papel da religiosidade na atividade sexual de 118 adolescentes, dos quais $67 \%$ eram sexualmente ativos e eles estavam envolvidos em vários graus com a religiosidade. Não encontrou relação entre religiosidade e comportamento sexual, ou cuidados com a prevenção da gravidez. Entretanto, os participantes com alto índice de religiosidade eram menos propensos a se envolverem em atividades sexuais e a considerar que tais atividades só deveriam ocorrer no contexto do casamento. Embora, na prática, muitos não respeitassem a última consideração e se mostrassem cientes de que há uma inconsistência entre suas crenças religiosas e sua atuação.

A relação entre religiosidade, consumo de drogas e enfrentamento entre adolescentes foi objeto da tese de Walker (2006) que partiu do fato dos trabalhos anteriores terem demonstrado que altos níveis de religiosidade diminuam a probabilidade do jovem passar a ser usuário de drogas. A Autora estudou o uso de estratégias de enfrentamentos comportamentais e cognitivos. Seus dados viabilizam concluir que religiosidade é efetiva no afastar o jovem das drogas mas há interação com os estilos de enfrentamento. 
CaNino (2006) fez uma análise exploratória da relação entre a teoria de "attachment", a religiosidade e a iniciação sexual precoce que traz muitos riscos para $\circ$ adolescente. Participaram de seu estudo 618 jovens universitários. Seus resultados revelaram que religiosidade e "attachment" (parental e romântico) são preditivos da $\mathrm{I}^{\mathrm{a}}$ experiência sexual.

Um estudo de meta-análise da produção sobre forma de religiosidade e níveis de risco para a saúde foi realizado por Hancok (2006) a qual localizou apenas 64 estudos publicados ao longo de 15 anos. Reitera-se assim o pouco investimento em pesquisa na área. A ênfase foi na categorização de conceito de religiosidade (149) e nível de risco. A relação entre os conceitos está dentro da margem de significância estatística mas não é unidirecional. Há contradição entre os estudos realizados.

A situação no Brasil mostra um grande vazio na produção sobre religiosidade e adolescência. Consulta feita a base de teses da CAPES (07/03/07) Resultou em nenhum trabalho específico. Consulta a SCIELO, na mesma data, também não viabilizou localizar nenhum artigo nacional específico embora, haja grupos pesquisando na área de Psicologia da Religião. Como lembram Paiva, Garcia, Gonçalves, Scala, Faria, Gomes, Jordão, Barbosa e França (2004) a experiência religiosa implica em complexos processos psicológicos e estudando artistas plásticos adultos, bem sucedidos apontam algumas possíveis vias de substituição. Quando e como isto pode ocorrer carece de estudos especialmente na fase crítica da adolescência.

Dos 25 artigos localizados via PsycINFO, cinco diziam respeito à relação entre religiosidade e uso de drogas entre adolescentes, problema social e de saúde mundialmente preocupante; quatro enfocavam a relação com a saúde e outros quatro com a vida sexual do jovem. Os demais textos se dispuseram nos seguintes temas: caracterização da religiosidade, religião e personalidade, ajustamento social e crise religiosa. Mais uma vez indícios de pouca produtividade e ausência de desbravamento sistemático do assunto se fazem notar.

Alguns exemplos ilustram a situação e as informações disponíveis. Herman-Stahl, Krebs, Kroutil \& Heller (2006) verificaram que baixa religiosidade tor- naram os homens mais propensos ao uso de anfetaminas sem prescrição médica; Lewis, Mellins \& Brackis-Cott (2006) constataram maior probabilidade de envolvimento em sexo com risco entre adolescentes com baixos índices de religiosidade; Schiff (2006) estudou o impacto do terrorismo, consumo de álcool e estresse entre adolescentes com religião e sem religião, encontrando maiores dificuldades de enfrentamento entre os religiosos. Os exemplos mostram contradição e variedade.

Lee, Miller, Chang (2006) realizaram um estudo exploratório sobre a identidade religiosa de 49 adolescentes coreanos cristãos americanos, de 14 a 19 amos. Encontraram correlações positivas com comedimento e realização e correlações negativas com falta de controle. Na pesquisa aqui recuperada este aspecto não foi objeto de atenção mais as poucas diferenças sugerem que seria interessante aprofundar esta questão especialmente em comunidades brasileiras de forte influência japonesa, coreana e chinesa nas quais muitos dos seus descendentes abraçaram 0 cristianismo ou mesmo mantêm duas religiões.

A preocupação com religiosidade, dinâmica da família e desenvolvimento na adolescência foi objeto do estudo de Regenerus e Burdette (2006) cujos resultados sugerem que o crescimento da religiosidade pessoal, indicam a importância da religião para o adolescente estão consistentemente relacionadas com melhores relações familiares, afastamento do álcool e de outras drogas.

Os exemplos mostram a diversidade de assuntos pesquisados, mas todos com baixa ocorrência, mesmo quando o tema é similar a variação metodológica dificulta uma síntese generalizável do obtido. Estas circunstâncias e considerando que dados colhidos com cuidado metodológico preservam-se além das teorias, os resultados do exercício transcrito ainda são úteis e podem sugerir outras pesquisas e a réplica da realizada.

\section{Referências}

Bear, G. G., \& Minke, K. M. (Eds.). (2006). Children's needs III: development, prevention and intervention. National Association of School Psychologists. 
Buskist, W., \& Davis, S. F. (Orgs.). (2006). Handbook of the teaching of Psychology. Malden (USA): Blackwell.

Canino, J. T. (2006). Using survival analysis to explore the relationship among attachment theory, religiosity and sexual initiation. Dissertation Abstracts International. Section A: Humanities and Social Sciences, 67(3-A), I 105.

Eghikudje, A .A. (2006). Relationship between religion and identity development: a study of second generation American Muslim adolescents. Dissertation Abstracts International. Section B: The Sciences and Engineering, 66(10-B): 5732.

Hancock, M. D. (2006). Forms of religiosity and levels of risk/ health-enchange ring behaviors among adolescents: a metaanalysis. Dissertation Abstracts International. Section A: Humanities and Social Sciences, 66(8-A): 284 I.

Herman-Stahl, M., Krebs, C. P., Kroutil, L. A., \& Heller, D. C. (2006). Risk and protective factors for nonmedical use of prescription stimulants and methamphetamine among adolescents. Journal of Adolescent Health, 39, 374-380.

Hostetter, M. P. (2006). The questing adolescent: an exploration of spiritual religious, clinical, and social factors that contribute to a questing orientation. Dissertation Abstracts International. Section B: The Science and Engineering, 67(4-B): 2258.

Jimerson, S. R., \& Furlong, M. (Eds.). (2006). Handbook of school violence and school safety: from research to practice. New York: Lawrence Erlbaum Associates Publishers.

Kaplan, H. (2006). Relationship between religion and identity development: a study of second generation American Muslin adolescents. Dissertation Abstracts International. Section B: The Sciences and Engineering 66(10-B): 5732.

Lee, J., Miller, L., \& Chung, E. S. (2006). Religious identity among Christian Korean-American adolescents. Psychological Report, 98, 43-56.

Leonard, K. C. (2006). Does religion play a role in adolescents' sexual activity? And investigation of high school seniors beliefs and behaviors. Dissertation Abstracts International. Section B: The Sciences and Engineering: 67(3-B), I731.
Lewis, L., Mellins, C. A., \& Brackis-Cott, E. (2006). Developmental ethic and social influences on participation in sexual possibility for youth with HIV-positive and HIV-negative mothers. Journal of Early Adolescence, 26(2), I60-I85.

Mulliken, B. L. (2006). Rape mith acceptance in college students: the influence of gender racial and religious attitudes. Dissertation Abstracts International. Section B: The Sciences and engineering, 66(II-B): 6285.

Paiva, G. J. de, Garcia, A., Gonçalves, A. K., Scala, C. T. , Faria, D. G. R. de, Gómez, M. L. T., Jordão, M. P., Barbosa, R. C., \& Franca, S. M. S. (2004). Experiência religiosa e experiência estética em artistas plásticos: perspectivas da psicologia da religião. Psicologia: Reflexão e Crítica, 17, 223-232.

Regenesus, M., \& Burdette, A. (2006). Religious change and adolescent family dynamics. Sociological Quarterly, 47(I), I75194.

Rodriguez, H. R. (2006). Social, cognitive, and attitudinal influences on birth control use among adolescents. Dissertation Abstracts International. Section A: Humanities and Social Sciences, 66(210-A), 3824.

Schiff, M. (2006). Living in the shadow of terrorism. Psychological distress and alcohol use among religious and non-religious adolescents. Social Science \& Medicine, 62(9), $2301-2312$.

Staats, A.cW. (1983). Psychology's crisis of disunity. Philosophy and method for a unified science. New York: Praeger Publishers.

Walker, C. (2006). Religiosity and coping: predictors of adolescent substance use. Dissertation Abstracts International: Section B: The Sciences and Engineering, 67(4-B): 2286.

Wepner, S. B., Grambrell, L. B. (Orgs.). (2006). Beating the odds: getting published in the field of literacy. Newark: IRA.

Geraldina Porto Witter (gwitter@uol.com.br) é orientadora de doutorado na Universidade Camilo Castelo Branco 